\title{
LA CIUDAD MODERNA ARTES Y CINE EN LA BUENOS AIRES DE LOS ‘60
}

\author{
LUIS DEL VALLE \\ Profesor de Historia y Proyecto FADU UBA Buenos Aires \\ https://dx.doi.org/10.12795/astragalo.2016.i21.08
}

Efervescencia. Modernización. Ilusión. Optimismo. Desarrollismo. Liberación. Mestizaje. Lisérgica. Amenaza. Revulsión. Clausura. Fulgor. Contracultura. Los años sesenta fueron, casi seguramente, los de una última carrera hacia el futuro; y fueron también el último intento de transformación de la cultura moderna concebido por la propia cultura moderna. Mañana puede ser el último día, hagámoslo ahora: esa tensión entre el imaginario de un futuro definitivo y la amenaza de cancelación de todo futuro hubo de ser uno de los fulgores de esos años. La Modernidad se ha constituido, invariablemente, como conflicto y como interpelación. Conflicto, el del armado de sus propias constelaciones y el de sus aporías; interpelación, en la de revolverse contra sí misma.

Aún como una cuestión didáctica, algunos historiadores, teóricos y pensadores, suelen organizar los despliegues en el tiempo y en el es- pacio bajo la forma de ciertas periodizaciones, o particularmente, por décadas. Contrariamente, los despliegues de la realidad se empeñan por escapar a tales sistematizaciones, derramándose, como sabemos, unos en otros, tejiendo relaciones indóciles, organizando otros dibujos espacio-temporales.

Podría pensarse así, para el siglo pasado, en una década extensa, que ocupara las entreguerras o una cierta continuidad entre los años '20 y '30; o en una década corta, la del ' 40 , circunscripta casi exclusivamente al desarrollo de la segunda gran guerra. Pero no obstante, también podría pensarse que la década del ' 60 contraviene tal afirmación. Ella se ha encargado de señalar una clara conciencia de época, un fondo histórico-cultural, un zeitgeist en particular, tal vez el último zeitgeist de la Modernidad, antes de su fragmentación y diseminación definitiva. 
La contundencia de su impulso le talla rasgos inequívocos, nada de ella se repliega sobre la década anterior ni se vuelca sobre la posterior; nada de la corrección y de cierta distinción de los '50 ni nada de la oscuridad ominosa de los '70 se presentan claramente en los '60. Y posiblemente nada haya definido con mayor lucidez a ese espíritu de época y su exacta ubicación como los límites señalados entre la consigna seamos realistas, pidamos lo imposible del Mayo Francés y la promulgada por John Lennon, el sueño terminó. Así, es que la cultura de los '60 es pasible de ser identificada como una formación propia, en sí misma, por la manera de constituirse y de armar un relato, por cómo ocurrieron una serie de hechos reunidos y a la vez enfrentados dentro de una producción atravesada por lo diverso. El reparto bipolar del mundo de posguerra, la guerra de Vietnam, los conflictos localizados como una forma de evitar pero a la vez de sustituir el conflicto final, la crisis de los misiles, el laberinto de la guerra fría frente a la linealidad del muro, o la pauperización de grandes extensiones del continente africano, fueron algunos de los fenómenos que convulsionaron al mundo durante la década del '60. Pero los mismos estuvieron también atravesados de otros emergentes que no dejaban de ser promisorios: el proceso de descolonialización en África y Asia, la Primavera de Praga, la Revolución en Cuba, los movimientos tercermundistas y el Concilio

Vaticano II, las revueltas estudiantiles que afloraban aquí y allá, o el Mayo Francés, entre otros, que potenciaban las componentes liberadoras en lo político, lo social y lo cultural. Los ideales de innovación, de cambio, de progreso y de desarrollo vuelven a encarnar en otra renovación de lo moderno. Pero a diferencia de otros momentos, como en los '20 y '30 o en los '50, la Modernidad incorporaba factores novedosos y a la vez se desprendía de ciertos sustratos del pasado y de su propia tradición. Las componentes de innovación, transformación y crisis desplegaban contenidos que los procesos de modernización del '20 o del '30 desconocían. La revolución sexual, la liberalización de la mujer y el feminismo, la difusión de las drogas como una instancia cultural, la asunción por parte de la juventud como una nueva conciencia de clase, las transversalidades disciplinares y las hibridaciones, la potencialización de los fenómenos de lo masivo -espectáculo, protesta, celebración política-, los cruces entre cultura popular y cultura de elite, o la presencia de los medios masivos de comunicación ahora con un alcance ilimitado, aparecieron como actores socio-culturales y con una presencia política antes no conocidos. Puede alegarse que costumbres liberales en el sexo, la reivindicación del rol de la mujer o el uso de drogas ya existían en otros momentos de la Modernidad del siglo $\mathrm{XX}$, pero nunca como en los ‘60 habían constituido una verdadera formación cultural que se expresara y ejerciera sus demandas de reconocimiento y legitimación.

Toda construcción cultural se define en el campo de un doble enfrentamiento, en el de la confrontación con la cultura oficial, y en el de la confrontación consigo misma. La Modernidad de los años '60 debía enfrentarse o interpelarse con algunos de los postulados formulados por la propia Modernidad, o contra lo moderno convertido ya en una tradición o en un repertorio -cultural, social, político, artístico- metabolizado. La década del '60 puede reaccionar o tensar así a la confianza mítica en el progreso técnico de fines de los años ‘ 50 , a los principios 
universalistas de la Modernidad del '20 o el '30, a la interpretación apolínea u olímpica de esas modernidades iniciales, a la supremacía del código de la abstracción estética, o a ciertas formas ya institucionalizadas de las relaciones entre cultura y sociedad.

Y en el mismo plano, es que podrá revolverse contra algunas de las aporías o modos de dominación acuñados por la misma Modernidad, algunas de ellas expuestas sin veladuras, otras ocultas bajo las formas de sus fantasmagorías. Una discusión y una reacción en términos masivos se darán a lo largo de la década en contra de las componentes de la alienación existencial, de la opresión política y social, de la pauperización de vastos sectores marginados, del efecto anestesiante y de disciplinador social ejercido por el consumo, o de la modernización del aparato belicista y su aplicación indiscriminada a escala planetaria. Pero a diferencia de otras revulsiones o confrontaciones en otros momentos, gran parte de la acción y reacción de los '60 se dará bajo las formas de la efervescencia y la vitalidad. Algo que estará atravesado de otro fenómeno inédito como fue el de la comunicación audiovisual masiva.

En esta construcción, los medios como la televisión, la radio, el cine, las publicaciones escritas o el periodismo - convertido en un medio en sí mismo- cumplirán un papel no sólo de difusión de los fenómenos, sino también de construcción de los mismos, atentos a las teorías y a los aportes de personajes como Marshall McLuhan, que no casualmente adquirieron tanta significación en la época. El despliegue y los efectos de la revulsión y de la contracultura -el hippismo, la cultura joven, el feminismo, la convulsión política, el pacifismo- van a convertirse así en los actuantes entre la denuncia y su conversión en producto, la iniciativa innovadora y su edulcoración, o entre el compromiso y el escepticismo, en una tensión entre afirmación y negatividad tal como la planteada por Adorno para los fenómenos culturales.

Este escenario general sucintamente planteado va a encontrar en el contexto latinoamericano, sobre todo en países como Argentina y Brasil, un panorama muy particular vinculado a las propias condiciones dadas en el momento. El capitalismo, los medios de comunicación, el consumo, la dominación política o social, los problemas de la marginalidad, van a ser tratados y experimentados en términos muy diferentes a los de ciertos países europeos o a los de los EE.UU, confrontando desde sus propias realidades sociales, económicas y culturales locales.

Toda la década del '60 va a ser vergonzosamente pródiga en los golpes militares que la asolaron y en las interrupciones democráticas, como el de Pérez Godoy en el '62 y Velasco Alvarado en el '68 en Perú, los de Branco en Brasil y Ovando Candía en Bolivia, en el '64, o el de Onganía en Argentina en el '66. Una realidad política que por otra parte no obedecía exclusivamente a las condiciones locales sino que se vinculaba a otros dictados de lo internacional, el orden bipolar, la doctrina de la seguridad nacional, el reparto en la organización internacional del trabajo o las sucesivas reconversiones del capitalismo.

En Latinoamérica, las fuerzas conservadoras fuertemente arraigadas, la alianza entre elite económica y elite política, la debilidad democrática y las conveniencias entre conservadorismo político, liberalismo económico y poder militar van a sumir al continente en la censura, las persecuciones, la tortura, o la mar- 
ginalidad. Superpuestamente, ciertos emergentes de modernización societal, de los mestizajes culturales, de los medios de comunicación audiovisuales, o de aquellas transformaciones democratizadoras antes mencionadas -feminismo, rol de la mujer, liberalización sexual, cultura joven, hippismo- van a configurar una trama heterogénea de fuertes contrastes y diversidades. En este contexto, los artistas locales van a dar cuenta a través de su arte de los conflictos de esa realidad, de los cambios políticos y de lo social, del lugar de lo institucional y de su interpelación.

El espacio para la manifestación de tales experiencias y prácticas va a ser, indudablemente, el de la ciudad, o más cabalmente, el de la metrópoli. Las articulaciones entre espacio metropolitano y artes, cine o literatura no resultaban novedosas; ya a partir de los años '20 en Buenos Aires, las obras de Xul Solar, Berni, March, Aizemberg, Borges, Arlt, Fernández, Christensen, Soffici, Sarraceni, Viñoly Barreto o Ferreyra habían dado cuenta de la metrópoli como escenario privilegiado de la cultura moderna del siglo XX, de sus imaginarios, de sus modos de apropiación, de los intereses en juego de sus diferentes actores, de las componentes de progreso o de amenaza, en un complejo tejido entre Modernidad, Modernización y Modernismo.

Pero la metrópoli de los años '60 se encuentra cargada de una serie de nuevos contenidos y factores que se corresponden con ese zeitgeist de la década, y que hubo de encarnarse en nuevas formas de producción y en renovados imaginarios artísticos, sociales y culturales. Las metrópolis latinoamericanas como Buenos Aires, San Pablo o México, van a desarrollar rasgos y cualidades ya diferenciados de la metrópoli del '20 o del ' 30 . En primer lugar van a acentuarse las formas de una modernidad de contrastes; el ideal de progreso y de un desarrollo universal preconizado por cierta modernidad inicial van a rebelarse como una promesa incumplida y van a confirmarse y potenciarse los contrastes producto de sí misma. Esos polos van a definir las tensiones entre las propuestas del desarrollismo característico de los países latinoamericanos de fines de los ' 50 y los ' 60 , por un lado, y la creciente tendencia a la miseria urbana, por otro. En ese despliegue, van a aumentar las condiciones de masividad de lo metropolitano, con índices y características que escapaban a los intentos de planificación y ordenamiento.

El sujeto colectivo masivo, la marginalidad como situación también masiva, el anonimato, la pérdida de los rasgos personales, la soledad existencial, el trauma o la enajenación, van a ser problemáticas no solo de carácter individual sino que se convirtieron en patologías sociales en los nuevos escenarios de lo metropolitano. Por otra parte, la ciudad va a ser también lugar del compromiso político. Frente a las condiciones del momento, el espacio público va a ser el escenario de la lucha, la resistencia, el activismo y la protesta social.

Sus actores van a ser en parte sectores ya presentes anteriormente en la protesta o el activismo, pero ahora en los ' 60 se van a sumar nuevos participantes con su presencia en el espacio público, muy diferentes entre sí y con demandas también diversas aunque en ocasiones concurrentes: manifestaciones estudiantiles, pacifistas, en contra de la discriminación racial o por nuevas reivindicaciones sociales. Aunque en el contraste de lo metropolitano las luchas sociales, el compromiso político o la demanda de reivindicaciones van a coexistir o compartir el espacio público con la exacerbación del con- 
sumo, los efectos ilusorios de la publicidad, la exposición y el fetiche, o la presencia de la moda ahora a escala industrial y masiva. La exaltación de las ideas de diversidad, de los diferentes sustratos sociales, de lo relativo a lo generacional, de los problemas de la identificación intersubjetiva y de grupos de pertenencia, van a tener su correlato con la diversidad en la moda y con su conversión en una producción industrializada y en serie, en una tensión también inédita entre la singularidad y la repetición infinita.

La metrópoli latinoamericana de los años '60 va entonces a convertirse en el escenario de un conjunto de valores y de características particulares asociados a esta nueva reconversión de la Modernidad y de las modernidades locales. Solamente en el lugar de la metrópoli pueden ocurrir o construirse ciertas relaciones o características, las del dinamismo, la alta densidad, las nuevas migraciones internas, la tensión, la concentración y la dispersión, la exacerbación, el acontecimiento, la irrupción de lo intempestivo, la heterogeneidad, las fusiones y los mestizajes, la superposición. Es en esos términos que la ciudad no debe entenderse meramente como un espacio, sino que construye lugar en tanto definición de diversos modos de apropiación, de relación o de identificación. De allí que en ese mismo sentido en realidad la metrópoli no sólo sea un escenario para el despliegue de la existencia moderna sino un actor cultural en sí mismo; allí no ocurre la Modernidad, la metrópoli es la Modernidad.

Entre fines de la década del '50 y principios de la del '70 la ciudad de Buenos Aires, como otras latinoamericanas, fue el centro de la llamada etapa del desarrollismo, proceso que cruzó y caracterizó a Latinoamérica como la promesa de progreso y bienestar en la segunda mitad del siglo, y que también fue el estertor de los ideales modernos, previo a la catástrofe y al dolor. Pero la promesa del desarrollismo, aunque incumplida en su propósito de bienestar generalizado, no obstante produjo una modificación de las estructuras productivas, económicas y sociales, dentro de un proceso de industrialización, de sustitución de bienes, de inversión y de consumo, y del crecimiento del sector industrial. En ese proceso es que se configuró la acentuación de una modernidad de contrastes, ya que el alto crecimiento económico y cierta modernización de las estructuras productivas se efectuó al costo de una mayor marginación, de la concentración de ingresos, de la eliminación de pequeños productores y establecimientos, y de la tercerización de la economía; la realidad de un mayor crecimiento pero también de una mayor desigualdad. ${ }^{1}$

Este despliegue claramente impactó en la configuración urbana de Buenos Aires. En los años '60 el ochenta por ciento de la población vivía en zonas urbanas, y Buenos Aires era la tercera ciudad en América Latina. El proceso de urbanización importó la descontrolada extensión de la mancha metropolitana, el aumento de las desigualdades, el crecimiento de las ghettizaciones y de las áreas marginales, la conversión de la pobreza rural o suburbana en miseria urbana y una enorme debilidad o carencia de calidad de vida en términos de servicios, infraestructuras, programas públicos y mejoras en la expansión de la suburbanización. Tales condiciones y despliegues van a construir un conjunto de imaginarios que solamente podían ser urbanos.

En su complejidad, la ciudad y el fenómeno de lo metropolitano trascienden de su realidad física, material u objetiva. Constitu- 
yen principalmente una realidad simbólica e intangible, el lugar de la simbolización y la connotación socio-cultural, de la configuración de códigos representacionales diversos y de sus modos de decodificación o de identificación por los diferentes actores del tejido; tejido no como realidad física sino como sistema de relaciones sociales y culturales de lo comunitario pero también de lo contrastante.

Una caracterización fiel de la efervescencia de la Modernidad de los ' 60 la dio la revista Primera Plana, al señalarla como la década frenética. Y en el contexto hasta aquí descripto el problema de la metrópoli de los años ' 60 , de sus imaginarios culturales y de sus expresiones artísticas y estéticas, no puede escindirse del fenómeno de la revolución cultural que los mismos significaron. Esas escenas finales de la felicidad moderna promulgadas en los ' 60 , y como último impulso transformador y visionario de la Modernidad del siglo XX, fueron las desplegadas por las ideas de la revolución cultural. Una revolución que en los imaginarios de la época señalaban, como ya dijimos, el optimismo en una visión de futuro, del porvenir, y en la confianza en el cambio, pero no solamente respecto de las estructuras tradicionales sino también de la primera Modernidad.

Pero que en su formación de contrastes, oponía o complementaba la enorme energía y efervescencia puesta en el cambio con la presencia también de un malestar, de un inconformismo y de una rebeldía propias de esa revolución en la cultura. La metrópoli como construcción cultural, la definición de sus escenarios, el lugar del espacio público, de sus instituciones, de su rugosidad y su texturalidad formal, espacial y existencial van a ser allí donde encontremos la expresión de la contracultura, de todas las manifestaciones de lo anti-institucional, ahora con una presencia y una fuerza autolegitimadora no conocida en ciclos anteriores. En el fenómeno de la contracultura son, paradójicamente si se quiere, las arremetidas de lo anti-institucional las que buscan ser reconocidas como un poder nuevo y alternativo, un poder indócil, cuestionador y rebelde, en ocasiones con propósitos y medios claros y definidos, otras sin un programa o modos perfectamente establecidos.

Es por eso que en Buenos Aires la contracultura describe una trama muy heterogénea, en la que podemos encontrar la literatura de Rodolfo Walsh, la música de Spinetta y de Los Gatos, el teatro de Griselda Gambaro, de Ricardo Halac y de Roberto Cossa, o el arte del Di Tella. Precisamente no se trata de igualar todas estas manifestaciones sino de resaltar la diversidad de experiencias y propuestas que presentaban una interpelación a lo institucionalizado.

Estos desarrollos se dieron en un contexto de confrontación y de tensiones entre los valores de una cultura ciudadana tradicional y los nueves emergentes urbanos. La Buenos Aires de fines de los años ‘ 50 y principios de los ‘ 60 mantenía un imaginario severo vinculado al paternalismo, el estreñimiento social, los prejuicios -sociales, religiosos, raciales, de clase, de género o generacionales- $o$ a ciertas tradiciones locales metabolizadas, respecto del rol de la mujer y del hombre, de la familia y su indivisión de la religión, del costumbrismo acendrado, de las formas de la recreación y del ocio, o de los modos de expresión culturales y artísticos. El paternalismo político y la debilidad de los valores democráticos y progresistas -expresados en los golpes militares, las democracias tuteladas y las prescripciones- se acrecentaron a media- 
dos de la década con el golpe de estado de Onganía y el paso más definido hacia la represión de manera directa: la cultura de los años ‘60 en Buenos Aires debió oscilar entonces entre los llamados de la cultura joven, la televisión, la revolución sexual, el hippismo y el feminismo, por un lado, y la presencia tutelar y represiva de la dictadura, por otro. Así mismo, otra tensión que puede verificarse en ese marco fue la existente entre los emergentes y las experiencias de la contracultura -como las expresiones artísticas y sociales de resistencia, las demandas de la juventud como clase en sí y su falta de representación, el descontento y el malestar social, las nuevas manifestaciones estéticas de vanguardia, el rol potencial de la televisión como medio omnipresente- y los intentos y las acciones por convertirlos en productos y objetos de consumo con el fin de metabolizarlos y eliminar su componente crítica, mediante las estrategias comerciales, las industrias culturales asociadas a la banalización, los productos edulcorados o políticamente correctos como fue en su momento por ejemplo, El Club del Clan. La llamada revolución cultural coincidió en Buenos Aires con otra revolución, la sexual. Se produjo a partir de allí una transformación sensible en las costumbres y en la vida cotidiana, con cambios en la moral sexual, en los comportamientos íntimos y públicos, en los roles de los géneros y en algunos tabúes como el divorcio o la independencia de la mujer, en donde el sexo aparecía de manera mucho más libre o desprejuiciada o como una inquietud de autoconocimiento.

La escena metropolitana expresó y a la vez potenció la construcción de la nueva sexualidad, a través de la moda, de los encuentros sociales y del esparcimiento, y de prácticas más desprejuiciadas, en el ámbito de la calle o en algunos espacios como en el de las confiterías y los snacks bars, las boites, los recreos al aire libre o los clubes y con toda una serie de publicaciones -Primera Plana, Panorama, Convicción- que trataban en el mismo plano que los problemas de la política o la economía los temas de la infidelidad, las relaciones extramatrimoniales o el placer sexual, todo ello en contra de la cultura institucionalizada, la influencia de la religión y los dictados de la moral.

Un conjunto de prácticas artísticas y del cine de la época van a dar cuenta de estas problemáticas dentro de un nuevo estado del arte, y se ha hablado de la producción de los años ‘60 como la de una vanguardia, similar o comparable con las vanguardias del '20. Más allá del término, existen entre las mismas claras diferencias en tanto experiencias culturales dentro de una mirada más conceptual y abarcativa. La Vanguardia de los '60 se presentó como un conjunto de experiencias menos herméticas, con un discurso en cierto sentido menos autónomo o volcado sobre sí mismo y más abierto a las posibilidades de una decodificación y asimilación a efectuarse desde el público. El propósito de un choque o de generación de un shock que provocara un llamado de atención o una toma de conciencia por parte del público encontraba una limitación menos restringida y un salto hermenéutico menos distante, y con posibilidades de que ese shock o la provocación sufrieran un menor nivel de rechazo.

En un nuevo estado de lo moderno, la liberalización de ciertas costumbres y concepciones culturales, la apertura a nociones más amplias de la existencia y de lo social y menos sometidas a las fuerzas conservadoras, el despliegue de la propia modernidad, habilitaba una acción con un mayor poder de penetración en 
la conciencia colectiva e individual del tejido social. La radicalidad de las Vanguardias del '20 y su distancia enorme respecto de una conciencia social llevaba generalmente al rechazo y al escándalo; en los '60 el escándalo habría de ser sustituido por otras reacciones frente a los estímulos provocadores, tales como la sorpresa, el humor, la ironía o el escepticismo.

Fue así mismo una vanguardia con un mayor espíritu lúdico, menos proclive a la radicalización y más próxima a un sentido festivo y del juego, aunque en muchos casos no renunciara a un compromiso político de transformación. Justamente, a diferencia de otras experiencias del Pop Art o del Arte Conceptual en Europa o en Estados Unidos, la vanguardia en la Buenos Aires de los ' 60 tuvo un impulso de compromiso político y de cambio del orden social, algo que al menos por parte de un sector de la misma se radicalizaría en la década del '70. En el caso de los Estados Unidos y de Europa, el desarrollo económico-social, el estado de bienestar, el impulso de las fuerzas progresistas institucionalizadas en equilibrio con el poder conservador, y la resolución de ciertas formas de lo político, hicieron de las Vanguardias de los ' 60 movimientos contestatarios o renovadores pero no desprovistos de cierta complacencia con el sistema, o al menos de ciertos beneficios que el mismo les otorgaba.

En el caso de Buenos Aires, como en el resto de Latinoamérica, el contexto de la opresión política, del sometimiento y de la marginalidad social, la debilidad democrática y la primacía de las fuerzas conservadoras, hicieron que las experiencias artísticas fueran canales de acción más vinculados con la denuncia de tales problemáticas. De tal modo, como tantas otras veces, es que las prácticas artísticas de los años '60 en nuestro continente en general y puntualmente en nuestro país, no puedan ser vistas como una mera traslación de otras producciones del exterior sino como una producción propia, localizada, con categorías, principios o procedimientos similares a aquellas pero con un fuerte sentido de localización en nuestras realidades en particular. Confluyente con esto, otra diferencia con las Vanguardias del ' 20 va a ser la importancia y el desarrollo adquirido por los medios de comunicación masivos, el cine y la radio, y la aparición de la televisión. Tales medios de comunicación tenían en los años '60 un espesor y un poder de difusión y de penetración incomparable con el de cuarenta años antes y que definían un campo de acción y de influencia sin precedentes en la construcción de opiniones, formas de producción y sistemas de legitimación para el tejido socio-cultural.

Dentro de la diversidad cultural que existía en Buenos Aires en los años '60 puede encontrarse también una extensa diversidad de experiencias artísticas en el campo de la plástica y de las artes visuales. Algunas de ellas tuvieron un propósito y medios concurrentes, pero lo que resalta para la época son dos ejes significativos. Por un lado la reformulación de ciertas tradiciones artísticas como en el caso de la pintura, con una revisión de las relaciones entre abstracción y figuración, una reelaboración de los elementos o de las componentes figurativas, o la manipulación del tema del soporte. Por el otro, muchas de esas propuestas y producciones abandonaron la pintura para introducirse en otras formas de expresión vinculadas al arte conceptual, como la instalación, el arte cinético, las intervenciones, el acting o los happenings, desestabilizando así los criterios de legitimación de la obra, el estatuto del 
arte o a la propia institución arte en sus modos de producción, difusión y recepción. Algunas de tales experiencias han quedado señaladas por la historia, como es el caso de la Nueva Figuración, la continuidad en el trabajo de Antonio Berni, el arte-cosa de Rubén Santantonín, el arte destructivo de Kenneth Kemble, la crítica socio-política de León Ferrari, el Di Tella, o las derivas de figuras como Alberto Greco, Héctor Puppo o Edgardo Vigo por señalar tan solo algunas de ellas. Con muchas diferencias entre sí, todas ellas fueron producciones incuestionablemente urbanas, indivisibles de los fenómenos de la metrópoli del ‘60, dando cuenta de algunos de sus rasgos o personajes, trabajando sobre la crítica social y la denuncia, u operando directamente en ella, en la ciudad, como un material en sí.

Las propuestas de la Nueva Figuración a partir de su muestra en la Galería Peuser en 1961 coincidieron con la agitación del campo estético en el contexto internacional de la época, con el debate acerca de los modelos de la abstracción moderna y su supuesta superación o agotamiento, con el Expresionismo Abstracto y el Action Painting de Pollock, De Kooning, Mark Rothko o Clyfford Still, o el Informalismo de Dubuffet o Tapies, y con el advenimiento de nuevas formulaciones producto del estallido de aquello conocido como pintura a partir de la segunda posguerra. En ese marco, la obra de Noé, de la Vega, Macció y Deira venía a superar las supuestas oposiciones entre abstracción y figuración ${ }^{2}$ y a dar cuenta de una denuncia social sobre el fenómeno de lo metropolitano. En obras como Introducción a la Esperanza o El Incendio del Jockey Club, ambas de 1963, la exploración de Noé con las distorsiones y las deformaciones, el uso de espejos cóncavos, y la monstruosidad de lo humano, se proponía la denuncia de un mundo y de una realidad alienante. Para Noé el caos era lo que estructuraba la obra pero también la vida. No lo entendía como un desorden, sino como otra forma del orden de las cosas en un estado de permanente movilidad. Operar en el caos y con el caos requería comprender la dinámica abstracta de un mundo en movimiento. Movimiento. Ruptura. Vitalidad.

Características que pertenecían también al fenómeno de la ciudad moderna en tanto exacerbación de la vida nerviosa y de un orden de lo urbano polifacético, contradictorio, riesgoso, pero también vital. No casualmente, esa ciudad, la Buenos Aires de su primera juventud, había sido el escenario de las grandes manifestaciones peronistas, de las concentraciones masivas que subyugaron a Noé como un movimiento y una ruptura del orden estático de lo establecido: la ciudad como el lugar de la primacía de lo emotivo-social que atrapa sensorialmente. En el caso de de la Vega, las articulaciones y traducciones entre arte y existencia hacían de la libertad un valor que no radicaba en un nuevo individualismo sino en un profundo sentido ético de la sociedad entendido como un cuerpo conflictivo, como una problemática punzante que interpelaba al artista como sujeto social involucrado. Esto lo llevó, por ejemplo, a negarse a participar en la Bienal de San Pablo del '69 en protesta contra la dictadura brasileña. En su serie Bestiario, entre el '63 y el '66, obras como Music Hall, Conflicto Anamórfico y Memoria de Sepulturero, muestran a través de la técnica del collage a animales quiméricos o fabulosos, distorsionados por el procedimiento de la anamorfosis, como una referencia a la condición humana, a las fuerzas ocultas que acechan al hombre, a sus propios monstruos internos. 
Monstruos, deformaciones u obsesiones que también ocupan la pintura de Macció: conflicto existencial, opresión, carácter sensorial de la densa materia pictórica como densidad existencial, expresionismo, en Cárcel=Hombre, de 1963; espacios ambiguos, ruptura de la unidad y fragmentación del cuadro en El Hombre Machacado, de 1962; la mismísima ciudad, anónima, densa, monótona, homotópica, sin cualidad, dentro de la cabeza fragmentada y del gesto de angustia en el alarido o a punto del vómito, en To live without a guarantee, del '63. Una ciudad en la que no hay manera de asegurarse, de organizar la armonía de la existencia, de eliminar la incertidumbre o la amenaza.....vivir sin garantía, o sin seguridad.

Ya desde los títulos de estas obras mencionadas se enuncia el problema existencial y la imposibilidad de una organización racional en la metrópoli contemporánea. La ciudad, en los años ‘60, ha renunciado ya a toda ilusión de un orden armónico como pretendió la Modernidad de los '20 o los '30 o el objetivismo de los planificadores. El imperativo benéfico del plan, del orden racional, del cientificismo aplicado a la existencia urbana, han caído desencantadamente y se ha revelado el orden cacofónico, heterotópico, opresor y amenazante, pero a la vez retador, inquietante, vital, exuberante, de la metrópoli. Obras como la ya mencionada Introducción a la Esperanza o Submundo, en este caso de Macció, levantan la mirada del artista como una respuesta a las demandas de las masas urbanas, exigiendo por sus derechos y convertidas en un sujeto político protagónico que solo se puede visibilizar, como acción política, en la ciudad. En un modo metonímico, ésta, no re-aparece entonces, no vuelve a aparecer, bajo su apariencia física o puro visibilista sino a través de sus protagonistas y ya no como una imagen de su realidad material sino como un paisaje social. En la metrópoli de los ‘60 el concepto de cultura de masas se convierte en un protagonista clave, siendo la masa aquellos sujetos indiferenciados, calculados, sin una cualidad propia y alienada ahora no solamente por la organización del trabajo y del ocio sino además por los medios de comunicación.

Hay por otra parte en estas obras una estetización del caos; el caos, lo anómalo, lo no consensuado, convertido en una expresión estética vinculada a lo barroco. Lo fabuloso, lo exuberante, la exacerbación de la carga expresiva, las anamorfosis, la supremacía de lo sensorial en la comunicación, fueron desde su origen en el siglo XVII cualidades de la estética barroca. Pero también han sido una de las formas de la modernidad entendida como desestabilización, como crítica a la corrección armónica y racionalista de lo moderno apolíneo; y ha sido también una componente constante de la cultura latinoamericana como cultura moderna. La pintura de la Nueva Figuración comparte su exuberancia barroca y su proliferación fascinante con otros artistas latinoamericanos como el chileno Roberto Matta, la cubana Antonia Eiriz o el venezolano Bárbaro Rivas.

Las series de Juanito Laguna y de $R a$ mona, de Antonio Berni, también fueron la expresión de una pintura urbana. En La Familia de Juanito, Villa Tachito, Villa Cartón o Las Navidades de Juanito, entre otras, hay un registro poético y político de la marginalidad, la desigualdad y las injusticias en la metrópoli contemporánea. En algunos casos las referencias eran directas, como las efectuadas a un área específica de la ciudad, la villa del Bajo Flores. En otros se trataba de una abstracción, como 
la apariencia dura, desnuda, fría, de la ciudad, expresada con los recortes y desechos de chapas oxidadas como fondo de un paisaje de marginación. Una marginalidad y pobreza no solamente expuestas en la apariencia figurativa de la pintura sino también por medio del collage con la utilización y la inclusión de materiales de desecho o desperdicios industriales producidos por la propia ciudad.

Lo urbano ya no coincidía con la celebración icónica de su brillo y esplendor, sino con la denuncia de sus excluidos, como también lo era Ramona. Las jóvenes marginadas, las prostitutas como víctimas explotadas por el capitalismo metropolitano, sus ideales y sueños, la ilusión de progreso: el collage en Berni no alude a una estética reconciliadora sino a la exposición de lo injusta y obscenamente expulsado por la ciudad. Exposición en tanto desnudez y crudeza de lo urbano interdicto por la corrección burguesa; expulsado pero a la vez recluido ante la imposibilidad de toda escapatoria.

De manera superpuesta a las indagaciones de la Nueva Figuración en el tejido cultural de la ciudad, la década del '60 estuvo signada en gran parte por las actividades del Instituto Di Tella. Las actividades del Di Tella expresaron en su conjunto la diversidad de cuestiones que los años '60 pusieron en juego, sus características, sus tensiones, sus contradicciones, su forma de interpelar y también de ser interpelados. El experimentalismo y la consagración de la novedad fueron dos de los rasgos de los años ‘ $60 \mathrm{y}$ del Di Tella en el sentido de volver a configurar los planteos de una vanguardia. Pero ese mismo experimentalismo y posibilidades vanguardistas no podían dejar de ser confrontadas con el antecedente de las vanguardias históricas y su capacidad para arrasar con todo lo conocido.
¿Cómo ser vanguardista luego de Duchamp, Baader o Tzara? Las vanguardias del '20 habían propuesto eliminar la existencia del arte en el conjuro de una fusión entre arte y vida. Cuarenta años después Romero Brest volvía a promulgar la necesidad de ese acercamiento entre arte y vida, efectuado en términos intelectuales, teniendo en cuenta el rechazo que las experiencias del instituto podían tener a causa de los prejuicios, los tabúes sociales y la solidificación de las costumbres. Así mismo, la consagración de la novedad corría el riesgo de asimilarse rápidamente a un juego dócil o indiferente. El poder de los medios de comunicación, para los ‘60 en general y el Di Tella en particular, cumplía un papel muy significativo como agentes para la metabolización acrítica de las propuestas artísticas y para su conversión en producto consumible, perdiendo su capacidad revulsiva o sus propósitos de concientización. Se ponía así en confrontación una dialéctica tensa entre la búsqueda de la innovación y el experimentalismo y su metabolización por parte de la institución.

La otra problemática en la que el Di Tella coincide con el zeitgeist de la época va a ser la de la transversalidad o la disolución de ciertos límites disciplinares. El arte moderno ha sido un arte que históricamente se desarrolló en la autonomía disciplinar, en la especificidad de cada disciplina. En la producción del Di Tella, lo mismo que en otras del exterior como con Fluxus o Yves Klein, no solamente contaba la pintura como disciplina hegemónica sino la mezcla o la contaminación entre distintas expresiones. Las artes visuales se entremezclaban con los medios de comunicación, la publicidad, la música, el teatro del absurdo, el diseño industrial, la moda, la literatura o el cine. Una práctica que en su sentido de mestizaje eliminaba las clasifi- 
caciones cerradas y trabajaba sobre la indeterminación o la idea de movimiento o de traspaso entre medios expresivos. Esto llevaba, por un lado y en algunos casos, a la sustitución de la idea del "objeto" artístico por la de la acción o la intervención; o a otras formas de trabajo por fuera de la pintura, la escultura o la música como disciplinas específicas y organizadas, tales como la instalación, la performance, el happening, las presentaciones multimedia o el juego. En ese medio mestizo, u opuestamente, tendiente a la disolución de los bordes, actuaron Marta Minujín con La Menesunda, las Canciones de la Informalidad de Marikena Monti y Jorge Schussheim, las canciones de Jorge de la Vega y Nacha Guevara, el teatro de Rodriguez Arias, Roberto Villanueva o Griselada Gambaro, los collage de música electrónica del CLAEM, o las producciones de Dalila Puzzovío, Edgardo Giménez, Roberto Plate o Rubén Santantonín.

Por fuera de la representación figurativa de la pintura, las acciones, performances o intervenciones del Di Tella eran claramente urbanas en su sentido de movimiento, sorpresa, diversidad, superposición, alteración o participación del público. En muchos de esos casos, la acción no se postulaba como un producto cerrado o terminado sino que, como en la ciudad, se completaba con la intervención del público. Un ejemplo de ello lo fueron Los Ascensores y Baño Público, de Roberto Plate.

Armados en la muestra del Museo de Arte Moderno en el '67, Los Ascensores eliminaban la categoría de obra y la categoría o la figura del artista como autor, ambas nociones integrantes fundamentales de la institución arte. La obra disimulaba el núcleo y las puertas de unos ascensores verdaderos, y el público formaba fila delante de ellos esperándolos, en una confusión o disolución de los límites entre la obra y la realidad. En Baño Público, en la muestra del Di Tella Experiencias 68, Plate construyó un local que simulaba un núcleo de baños mixtos con un espacio interior con seis boxes $\sin$ artefactos. Lo novedoso e inesperado fue como la gente que entraba escribía o dejaba anotaciones en las paredes o las puertas, como sucede muchas veces en los sanitarios públicos; inscripciones o mensajes en contra de la dictadura de Onganía y que originaron la clausura de la obra.

La instalación, operada o intervenida por el público, se completaba justamente con su intervención y eliminaba los límites precisos entre lo real y la simulación. La gente se apropiaba y reproducía una acción de la realidad, como escribir en los baños, modificando la relación convencional entre artista-productor y públicoreceptor y el concepto tradicional de autor.

El mestizaje o las mezclas artísticas que importaban estas prácticas coincidían con la cultura de acumulación, sedimentación, mestizaje o mezcla característica de una ciudad como Buenos Aires y su fuerte condición cosmopolita. Tal como ha argumentado Andrea Giunta ${ }^{\bigotimes}$, en la base de las transformaciones artísticas y socioculturales de los ' 60 se encontraba la vocación de un ideal o imaginario cosmopolita. Ser actual, ser moderno, implicaba un cosmopolitismo partícipe de la cultura internacional.

A fines de los años '60 el Di Tella se disgregó, como consecuencia de los diferentes intereses de sus integrantes pero fundamentalmente como producto de las propias contradicciones y complejidades del debate cultural de la época. Muchos de sus miembros asumieron una radicalización política progresiva cada vez mayor, con la migración a posturas más extremas 
como en el caso de Tucumán Arde. De una forma $\mathrm{u}$ otra, lo que se estaba poniendo en discusión -y fuerte confrontación- eran las relaciones entre arte y política, el rol del arte y una mirada crítica sobre su propia idea u objeto. En cierto modo, el Di Tella había seguido siendo una forma de la institución, más allá de sus posturas contestatarias. El tema institucional no radicaba en pertenecer o no a las corrientes tradicionalmente legitimadas o en el acto revulsivo sino que el instituto seguía sosteniendo una concepción del arte como representación o expresión. En sus obras, en sus acciones o puestas, al igual que en el arte tradicional, seguía manteniéndose la idea de la contemplación de algo único, irrepetible, aurático o singular. Lo disruptivo metropolitano, lo que posteriormente Solá Morales llamará lo intempestivo, se correspondía con lo disruptivo de las experiencias artísticas, pero en esa disrupción no dejaba de radicar una singularidad. Las manifestaciones artísticas del Di Tella podían llevar adelante una "representación" de lo masivo, lo popular, lo banal o lo cotidiano urbano, pero no constituían un producto de lo masivo, lo popular, lo banal o lo cotidiano. Su modo de concepción, producción y circulación seguía siendo elitista, parcial o institucional. Frente a ello podía pensarse en la existencia de otro arte o de otra concepción de lo que constituía lo artístico o un nuevo paradigma estético.

Era el otro arte el verdaderamente originado en los productos masivos, como la historieta -Pratt, Oesterheld, Breccia, Solano López-, la canción popular -el rock o la música melódica-, las fiestas o expresiones populares en la calle, o la moda. Una sociedad de masas, y la construcción cultural de la ciudad cosmopolita, ya no podían dirigirse meramente a la con- templación de la reproducción infinita de una obra que en definitiva seguía siendo única -tal como planteara Benjamin treinta años antessino que pasaba a elaborar sus propios productos artísticos y culturales. Teorizado por Oscar Masotta, Anibal Ford o Heriberto Muraro, los modos de expresión y de construcción cultural de lo metropolitano se dirigían hacia un cambio en el concepto de cultura.

La ciudad formaba un texto para ser leído y operar con él. Se trabajaba con objetos o elementos encontrados, mediante la técnica del bricolage, con su reapropiación y resignificación, como hemos visto en algunos casos. Pero también se desplegó una reapropiación y resemantización de los espacios de la ciudad bajo las formas de un arte participativo en el mismo espacio público, exterior o interior.

Para Héctor Puppo se trataba de trabajar en el espacio abierto de la calle como un medio artístico y constructor de una nueva estética, extrayendo de allí los estímulos y el material en esa reformulación entre artistaautor-público-participante-concepto de arte. La calle es el lugar que en su caos genera vida, sentidos y experiencias estéticas; la calle es la sociedad, y si en su espíritu vanguardista los artistas querían transformarla, debían actuar en el espacio de la calle. La misma es, entonces, lo público imprevisto, el acontecimiento, algo más que un espacio de circulación o de intercambio cotidiano metabolizado para comenzar a ser significante-significado. Y en el contexto de las hibridaciones o de las contaminaciones disciplinares y de la actitud revulsiva, la transgresión de los géneros discursivos preestablecidos importaba la ruptura de todo relato totalizador, de toda narración reificadora; el estallido de los grandes relatos unificadores y el inicio 
de las microhistorias coincidía con el estallido y la fragmentación de lo metropolitano. En La Plata, con la ciudad como un campo en el que actuar, Puppo lleva el arte a la calle, interviniéndola con pinturas, dibujos e inscripciones en las veredas, pero también utilizando otros medios y cambiando los lugares de expresión o de acción. En la Noche de San Juan realiza una instalación en un almacén, con velas encendidas, estampitas y series de objetos cotidianos que se reparten entre la gente que no necesariamente se acercaba a participar. Todas sus intervenciones, su arte de acción, sus experimentos con el arte conceptual, junto con los integrantes del Grupo Si, se hallaban dirigidas a producir una reflexión irónica acerca de la sociedad de consumo y del mercado del arte.

Otro exponente de las intervenciones o del arte urbano va a ser Edgardo Vigo. Su modus operandi lo constituía la toma de objetos encontrados en las calles y su inclusión o transformación en obra, y las operaciones realizadas directamente en el espacio público dejadas como marcas. Nuevamente el propósito era cuestionar el marco institucional: los sistemas de validación acerca de lo que es una obra, la idea de obra maestra, y las nociones de obra-producto dentro de un circuito mercantilizado. Los procedimientos para el armado de sus objetos eran el collage, los montajes o el bricolage, con formatos de panfletos, manifiestos, acciones corporales o montajes fotográficos, tales como La Medusa Trogloclusa o Aparato para alimentar y dormir nenes época paterna. También construyó y montó sus series de Máquinas Imposibles -Máquina imposible para triplicarse o unificarse, Máquina imposible para buscar princesas, Máquina imposible para la siembra de engranajes, entre otras- y de Máquinas Inútiles -Cargador eléctrico, Máquina para batir records de velocidad establecidos por sillas de ruedas de lisiados- con claras referencias a las producciones de Dadá o del Surrealismo. En cuanto a la ciudad propiamente dicha, Vigo la consideraba como un "cuerpo urbano" que estaba cruzado por una memoria y una biografías colectivas, un cuerpo en el cual quedaban grabadas las acciones, los pensamientos, los deseos y las vivencias del sujeto urbano.

Además de efectuar muestras en lugares no convencionales - un club, una boite, un cine, un salón de bailes- la acción directa en la calle constituía un atentado contra la institución museo. A partir de cierto momento comienza a operar en las calles de La Plata haciendo señalamientos de ciertos objetos, lugares o situaciones banales o cotidianas, como en el caso de Manojo de semáforos, en una esquina de la ciudad. La urbe moderna es el lugar para el asombro, la perturbación o la manipulación lúdica, y sus calles son un territorio en disputa: allí se conjugan o se repelen la expresión popular, la represión, la lucha sindical, el ocio o el arte. Nuevamente, como en los casos anteriores, en Vigo convergen lo transdisciplinar o las hibridaciones, el arte, la sociología, la política, la filosofía, lo proto-ecológico, en una mezcla de diferentes sistemas de producción de signos.

El cine de los años '60 también va a ser una expresión de lo metropolitano y lo cosmopolita de Buenos Aires. Con influencias de la Nouvelle Vague, de Bergman y de Fellini, el cine para muchos de los espectadores porteños -sobre todo aquellos que se ubicaban en una elite cultural ciertamente sofisticada y que no necesariamente se correspondían con una elite económica-social- no solo constituía un pasatiempo sino que era el destinatario y a la vez 
el promotor de un interés intelectual y cultural. Esa relación entre cine y ciudad fue una de las marcas constitutivas de la generación del ‘60 con autores como Simón Feldman, Rodolfo Kuhn, Fernando Birri, Leonardo Favio, Lautaro Murúa, Miguel Antín, David Kohon o Leopoldo Torre Nilsson. Como generación de cineastas, la del '60 fue la de un cine autoral, con otras premisas formales y narrativas muy diferentes a las de los ' 40 y ‘50, en donde la obra era el instrumento de un señalamiento crítico-reflexivo también en contra de la institución del cine de géneros y del sistema de estudios y grandes estrellas. Tal componente crítico-reflexiva hacía del cine un instrumento para bucear en la realidad social y en el universo interior del sujeto. Los lugares de la ciudad se rarifican, y sus personajes son mayormente seres atravesados por lo existencial, atribulados, enigmáticos, presas de un malestar que no puede separarse de las condiciones de la existencia urbana moderna. Esos problemas existenciales, como la alienación, la neurosis, la convulsión, la incomunicación, el escepticismo, o lo enigmático del trauma, solo pueden ser producto de la vida en la ciudad. Películas como Circe, Los jóvenes viejos, La Terraza, El dependiente, La cifra impar, Tres veces Ana o Prisioneros de una noche, pueden trabajar tanto a la ciudad como un personaje en sí mismo como a través de los sujetos individuales o colectivos que la habitan. Como un personaje por sí mismo, la ciudad adquiere y sufre un proceso de animación y de transmutación, como el lugar de la incertidumbre, la felicidad, la soledad, la enajenación, la promesa, la conspiración, la amenaza o la muerte. En cuanto a los personajes que la habitan, los mismos parecen poblarla sin un arraigo afirmativo al tiempo o al lugar. Seres muchas veces que derivan, como cuando alguien se pierde en la ciudad, en su incertidumbre, su angustia, su voluntad férrea o su perplejidad. Personajes que exponen o que esconden una contradicción entre una densidad existencial extrema y una apariencia de levedad inerte; contradicción entre densidad y levedad que también es propia de la ciudad.

En La Terraza, de Leopoldo Torre Nilsson, de 1963, se conjugan la ciudad, el espacio y la organización social en una mirada crítica sobre la Buenos Aires de la época. En la presentación de algunos elementos de la narración, la época queda señalada: jóvenes en una terraza, sol, todavía, en 1963, no el rock, sino el bossa nova.

La ciudad aparece en los espacios urbanos de la ciudad elegante y de la elite: las avenidas Figueroa Alcorta o Libertador, Palermo, la Facultad de Abogacía, el Velódromo, la sede central del ACA, las confiterías; condensadores urbanos de un sector de la ciudad en donde se identifican claramente lugar y clase social. La historia transcurre en la terraza de un edificio de categoría de la Avenida Figueroa Alcorta y allí se desarrolla la crítica social que propone la película.

En la organización interna del edificio, en la relación entre los propietarios y el personal o en las escenas de un velatorio, se ponen en evidencia los principios y los modos de la estructura social. Los jóvenes que se reúnen en la terraza del edificio dan cuenta de la existencia de ese nuevo integrante de lo social, la clase joven urbana, que forma una categoría en sí misma, con sus características, sus lógicas de funcionamiento y sus preferencias. Esos personajes pertenecen a las clases altas, y son elitistas, hedonistas, racistas, discriminadores, también contradictorios. Se juega allí una tensión en el orden social de la metrópoli de los ‘60, 
inédita hasta el momento, ya que esos jóvenes pertenecen y conservan modos o características de una clase alta tradicional, en su desdén, en su indolencia, en su impunidad, pero también ya se diferencian de ella en su propio comportamiento. La ciudad es entonces el lugar de la intolerancia, de la indolencia existencial y de una confrontación social.

En principio se enfrentan allí: el mundo del ocio, de la indolencia -jóvenes sin expectativas, sin compromisos-, o de la intolerancia -jóvenes que discriminan y se ponen violentos con el otro externo y diferente-, de una clase patricia o de la alta burguesía, y el mundo del trabajo asociado al abuso, el desprecio o la burla. En la terraza se juega entonces la mirada crítica sobre una clase en decadencia. Pero además del lugar de la confrontación, la ciudad es el ámbito de otras formas de relación entre esos distintos agentes de la sociedad. Ellos no solo se vinculan por el sometimiento o el desprecio de unos sobre otros sino también por vínculos más sutiles, más tangenciales o velados: el interés mutuo, los acuerdos parciales, o las pequeñas revanchas.

En otro film, Prisioneros de una noche, de David José Kohon, de 1960, la ciudad y lo metropolitano construyen otro tipo de mirada. Aquí la ciudad se extiende hacia el conurbano en un nuevo ciclo de la expansión metropolitana, hacia Caseros o Santos Lugares con los típicos remates de lotes de los ' 60 , en donde se conocen ambos protagonistas. En el desarrollo de la película, se confrontan entonces en esa expansión de la mancha urbana las tensiones entre centro y periferia, tensiones que han atravesado toda la historia de la ciudad desde mediados del siglo XIX. El bullicio, la concentración, el dinamismo, la densidad, la heteroge- neidad del centro, frente al reparo, le lentitud, la apertura casi infinita, el vacío del suburbio. Las diferentes espacializaciones del film señalan esa confrontación: la Avenida Corrientes, el Abasto, Retiro, la vida nocturna, por un lado, los suburbios, el tejido abierto, la estación de tren, la vida de día, por el otro.

Pero esa confrontación no es solamente la de dos opuestos o formas de vida antagónicas, tales términos son también complementarios dentro del ciclo de lo moderno y de su proceso de antropización del territorio. Uno de los personajes, una bailarina de locales nocturnos, sale al suburbio en busca de cierto sosiego y tregua para la alienación de su vida; el otro, un grupí que es un peón del sistema económico de la especulación inmobiliaria. Ambos personajes son seres alienados, sometidos a la soledad, la incomunicación, o la resignación propias de la gran ciudad. La ciudad es ahora el lugar de la amenaza y de ese otro lado oscuro de la Modernidad. Las calles, las plazas, los portales de las casas, han dejado de ser el espacio de la sociabilidad y del encuentro, y en una transmutación, se han convertido en lugares amenazantes, escenarios del peligro, el miedo, la irracionalidad, o el crimen. La ciudad no responde al ideal moderno en tanto lugar de la productividad, la armonía, la seguridad, la pertenencia o el equilibrio social, sino donde radica el desamparo, la soledad, la marginalidad o la incertidumbre. No son espacios de lo desconocido, no constituyen el temor por lo no conocido sino que son siniestros, en tanto aquellos lugares reconocibles, del afecto, o conocidos, se han vuelto inciertos, amenazantes.

Sus habitantes son la gran masa anónima o desconocida o figuras de lo marginal urbano: mafiosos, estafadores, delincuentes, ju- 
gadores, vividores, cafishios. Todos mienten dice la protagonista en un momento del film. Ambos personajes atraviesan la ciudad en una deriva, en un devenir sin rumbo fijo, en una noche de alivio, de ilusión, de miedo, de promesas, de incumplimiento, en todo aquello de provisorio o efímero que tiene la metrópoli.

Tres veces Ana es otro film de Kohon, del año 1961, dividido en tres historias autónomas pero que se articulan en la ciudad como personaje central. En la primera de ellas, La Tierra, la ciudad es el escenario para el transcurrir de la experiencia en el amor, el trabajo y el ocio, en una confrontación entre el espacio interior -intimista, costumbrista, de la permanencia de las cosas, de un lento transcurrir del tiempo-y el espacio exterior, el de la metrópoli -con el movimiento, el cambio, la velocidad, lo provisorio-. Esa ciudad no es ni buena ni mala, no es el lugar de la armonía o el equilibrio ni el lugar de la amenaza o el mal, sino un lugar dado por la indeterminación, un espacio abierto al despliegue de las experiencias. Pueden allí ocurrir la angustia, el juicio moral, la hipocresía, el vacío, el desencanto, la esperanza. El segundo episodio, El Aire, da cuenta del espacio del suburbio como una alternativa a la ciudad. En la lógica del desarrollo urbano de los años ' 40 y ‘50 la ciudad se ha expandido, en este caso hacia el norte, y en los años '60 toda la costa de Vicente López, Olivos, Martínez o San Isidro es el lugar del esparcimiento al aire libre, del contacto con la naturaleza, de los balnearios sobre el río, de los boliches y paradores, de día y de noche, sobre la costa. Una vida alternativa y a la vez paralela a la de la ciudad central, la otra cara del mismo fenómeno del desarrollo de lo metropolitano. La vista al exterior, la playa la naturaleza ya son una construcción cultural, se encuentran culturizadas, lo mismo que el lenguaje o la apariencia de lo exótico de los boliches, los clubes nocturnos o de cierta arquitectura en una relación entre naturaleza, exotismo y producto.

En ese mundo en que pareciera vivirse perpetuamente al exterior -recreación de un posible paraíso- se despliega una vida paralela a la del centro de la ciudad, asociada a la recreación, la disipación, el absurdo, ciertas situaciones límite, los inicios de la liberación sexual, el compromiso y lo superficial, la búsqueda por parte de los personajes de emociones, pero también de un destino, o de un lugar. Por último, en el tercero de los episodios, La Nube, la película se centra en la gran urbe, la cual se haya representada por los programas modernos -el rascacielos, el diario, las terminales de tren, los bares al paso- la gran densidad poblacional y lo multitudinario, y las largas visiones peatonales y a vuelo de pájaro de la concentración metropolitana.

Esa densidad metropolitana vuelve a ser el lugar de la soledad, del aislamiento, de la incomunicación y de la dificultad del encuentro con el otro. Pero también puede ser el espacio de la fantasía o de la alienación producida por la soledad y el deseo. En la ciudad y sus laberintos existenciales pueden confundirse la realidad y la fantasía, cuando el protagonista descubre que la mujer de la cual se ha enamorado, la mujer depositaria de sus afanes, es en verdad un maniquí ubicado en una ventana. Siguiendo una larga tradición respecto de la figura del autómata o de la muñeca -El Hombre de Arena, El Jugador de Ajedrez, El Hombre de Palo, La Eva Futura, Metrópolis- es también la ciudad moderna en donde se verifica la disolución de lo humano, su artificialidad, su pérdida de humanidad aun conservando su apariencia. Como 
en las palabras del protagonista: Mejor vivir de mentiras, como un zombie...... ¿Ustedes creen que eso es una ciudad?... Es un gran club de zombies, un campamento de fantasmas...

\section{NOTAS}

1 Para un estudio del desarrollismo en Argentina puede consultarse el trabajo de Susana Torrado, Estructura Social de la Argentina. Buenos Aires. Ediciones de la Flor. 1992.

2 Nos referimos a una supuesta oposición ya que en el despliegue de las artes plásticas del siglo XX, si pensamos en casos como los de Picasso, Klee, Magritte, Chagall, Brancusi o Muybridge, tal confrontación nunca fue real, sino más bien una preocupación de críticos, teóricos e historiadores. 3 Noé, Luis Felipe. Mi Viaje, y Cuaderno de Bitácora. Buenos Aires. El Ateneo. 2015.

4 Giunta, Andrea. Vanguardia, internacionalismo y política. Arte argentino en los años sesenta. Buenos Aires. Paidós. 2001. 